\title{
The Loading Control Strategy of the Mobile Dynamometer Vehicle Based on Neural Network PID
}

\author{
Xianghai Yan, Liyou Xu, and Yuan Wang \\ College of Vehicle and Traffic Engineering, Henan University of Science and Technology, Luoyang 471003, China \\ Correspondence should be addressed to Liyou Xu; xlyou2002@sina.com
}

Received 23 February 2017; Accepted 26 April 2017; Published 17 May 2017

Academic Editor: Antonios Tsourdos

Copyright (C) 2017 Xianghai Yan et al. This is an open access article distributed under the Creative Commons Attribution License, which permits unrestricted use, distribution, and reproduction in any medium, provided the original work is properly cited.

To solve the problems of low loading precision, slow response speed, and poor adaptive ability of a mobile dynamometer in a tractor traction test, a PID control strategy based on a radial basis function neural network with self-learning and adaptive ability is proposed. The mathematical model of the loading system is established, the algorithm of adaptive control is described, and the loading control method is simulated with MATLAB software. The system, which uses the NN-PID (neural network PID) control strategy, is used to test a YTO-MF554 tractor. Then, the proposed control strategy is validated. Results show that when the traction increases from 0 to $10 \mathrm{kN}$, the response time of the test system is $1.5 \mathrm{~s}$, the average traction force in the stability range is $10.13 \mathrm{kN}$, and the maximum relative error of traction force is $2.2 \%$. This control strategy can improve the response speed and steady-state accuracy and enhance the adaptive ability of the mobile dynamometer vehicle loading system. This study provides a reference for designing the adaptive controller of the mobile dynamometer vehicle loading system.

\section{Introduction}

The loading process of mobile dynamometer vehicles presents many uncertainties in the tractor traction test. Frequently tuning the parameters is necessary for traditional control methods, thus disrupting the test. Moreover, the traditional system has low efficiency and accuracy. A considerable number of theories and practices have shown that the application of self-adaptable control technology to the test system will improve the efficiency and accuracy of the test system [1-4].

The adaptive control algorithm and its application have been studied by many local and international researchers. Locally, Wang et al. proposed the fuzzy adaptive PID control for the nonlinear and time-variant mobile dynamometer of an automobile [5]. He et al. expounded the output prediction of complex nonlinear systems based on the radial basis function (RBF) neural network and obtained well-predicted results [6]. Xia and Wang proposed a new method that combined the RBF neural network and single neuron PID. This method was applied to the speed control of a switched reluctance motor with good control effect [7]. Wang et al. applied RBF-PID to improve the temperature control of a thermal power plant [8]. Internationally, Anwar optimized
PID controller parameters based on a genetic algorithm and achieved accurate real-time control for retarder loading [9]. Dash et al. expounded the application of the RBF neural network PID in controlling an electrical power unit [10]. D. L. Yu and D. W. Yu investigated the adaptive adjustment algorithm of RBF neural networks [11]. However, there are few studies on the adaptive control of loading for a mobile dynamometer vehicle in the tractor traction test.

In this study, the RBF neural network PID control strategy is used for the load control of the mobile dynamometer vehicle. The system output traction has a good follow effect in comparison with input load. And the output load for power wagon random loading system can reproduce the tractive load for tested tractor reasonably. This control strategy can improve loading precision and response speed and enhance the self-adaptive ability of the control system. This method can also provide a reference for the investigation of mobile dynamometer vehicle loading control.

\section{Mathematical Model of the Mobile Dynamometer Vehicle Loading System}

The mobile dynamometer vehicle is modified with a YTO1304 tractor. The tractor power take-off is connected to 
an electric eddy current retarder, which brakes the mobile dynamometer vehicle by loading the transmission system.

2.1. Model of the Eddy Current Retarder. The eddy current retarder is mainly composed of front and rear rotor disks and eight excitation coils with an iron core between the disks. The following simplifications and assumptions are made when the loading torque of the retarder is calculated: the rotor disks are simplified as annular plates; the magnetic field that is produced by the coil is only distributed in the circular region and magnetic flux leakage is ignored; the relative permeability of the rotor disk is considered constant; and hysteresis losses and magnetic saturation are ignored. A detailed deduction is presented in [12], wherein the loading torque is denoted by the following:

$$
\begin{aligned}
& T_{d} \\
& =\frac{90 \sqrt{2} N_{p}\left(\rho \mu_{0}\right)^{3 / 2}(N I)^{2} \pi^{3} d^{4} \sqrt{\omega}}{\sqrt{\mu_{r}} \arcsin \left(d / 2 R_{l}\right)\left(16 \pi \rho l_{g}+\sqrt{2} k_{e} \mu_{0} \sqrt{2 \rho / \omega \mu_{0} \mu_{r}}\left(\pi d^{2} / 4\right) \omega\right)^{2}},
\end{aligned}
$$

where $T_{d}$ is loading torque, $\mathrm{N} \cdot \mathrm{m} ; N_{p}$ is the number of magnetic pole pairs; $\rho$ is the resistivity of rotor disk, $\Omega \cdot \mathrm{m} ; \mu_{0}$ is the permeability of the vacuum, $4 \pi \times 10^{-7} \mathrm{~N} \cdot \mathrm{A}^{-2} ; N$ is the number of turns of excitation coils; $I$ is the excitation current, $\mathrm{A} ; d$ is the magnetic core diameter of the excitation coil, $\mathrm{m}$; $\omega$ is the angular velocity of the magnetic field changes, $\mathrm{rad} / \mathrm{s}$; $\mu_{r}$ is the relative magnetic permeability of the rotor disk; $R_{l}$ is the distance between the center of the magnetic pole and the center of the rotor disk, $\mathrm{m} ; l_{g}$ is the width of air gap m; and $k_{e}$ is the conversion rate ( $k_{e}$ usually takes 1.5$)$.

Given that $\omega=2 \pi N_{p} n / 60$, the loading torque is simplified as follows:

$$
T_{d}=\frac{k_{1} I^{2} \sqrt{n}}{\left(k_{2}+k_{3} \sqrt{n}\right)^{2}},
$$

where $k_{1}, k_{2}$, and $k_{3}$ are parameters that are related to the structure and material of the eddy current retarder.

A simplified derivation of the retarder transfer function is as follows: the excitation coil of the eddy current retarder can be simplified as the resistance and inductance in series [13]. Therefore, the transfer function of the excitation voltage and current is as follows:

$$
\frac{I(s)}{U(s)}=\frac{1}{L s+R}
$$

where $L$ is the coil inductance of the eddy current retarder, $\mathrm{H} ; R$ is the coil resistance of the retarder, $\Omega$; and $U$ is the excitation voltage, $\mathrm{V}$.

A simplified method for establishing the transfer function of the DC dynamometer is based on [14]. The eddy current retarder with nonlinear properties can be simplified as a linear element with the assumption that the change rate of the excitation current is approximately constant when the excitation voltage changes. Combining (2) and (3) yields the transfer function of the retarder:

$$
\frac{T_{d}(s)}{U(s)}=\frac{2 k^{\prime}}{s(L s+R)} e^{-\tau s} .
$$

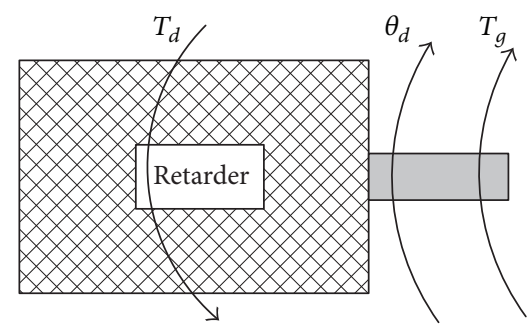

Figure 1: Variable symbols of the retarder.

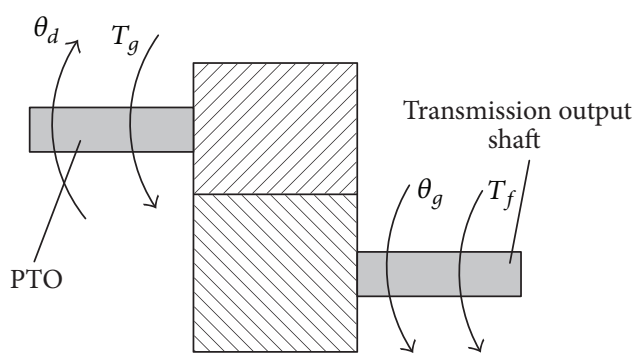

FIGURE 2: Variable symbols of gear pairs.

In the formula, $k^{\prime}$ is a variable, which is related to the structure, material, and current change rate of the eddy current retarder.

\subsection{Model of Loading Transmission System}

2.2.1. Eddy Current Retarder. The moment of inertia of the rotor disk is considered in establishing the transfer function of the retarder. The retarder is a brake component, which is an external drive that provides power. The dynamic variables of the retarder are shown in Figure 1.

$$
J_{d} \frac{\mathrm{d}^{2} \theta_{d}}{\mathrm{~d} t^{2}}+T_{d}=T_{g}
$$

where $J_{d}$ is the moment of inertia of the retarder rotor disk; $\mathrm{kg} \cdot \mathrm{m}^{2} ; \theta_{d}$ is the rotation angle of the retarder rotor disk rad; $T_{g}$ is the input torque of the retarder $\mathrm{N} \cdot \mathrm{m}$; and $T_{d}$ is the loading torque of the retarder N.m.

2.2.2. Gear Pairs. The system variables of the gear pairs are shown in Figure 2.

$$
\begin{aligned}
T_{f} & =J_{g} \frac{\mathrm{d}^{2} \theta_{g}}{\mathrm{~d} t^{2}}+B_{g} \frac{\mathrm{d} \theta_{g}}{\mathrm{~d} t}+T_{g} i_{g} \\
\theta_{g} i_{g} & =\theta_{d},
\end{aligned}
$$

where $J_{g}$ is the moment of inertia of gear pairs, $\mathrm{kg} \cdot \mathrm{m}^{2} ; B_{g}$ is the damping coefficient of the friction torque, $\mathrm{N} \cdot \mathrm{m} \cdot \mathrm{s} \cdot \mathrm{rad}^{-1} ; \theta_{g}$ is the rotation angle of the transmission output shaft, rad; $i_{g}$ is the transmission ratio of the gear pair; and $T_{f}$ is the torque of the transmission output shaft, $\mathrm{N} \cdot \mathrm{m}$. 
2.2.3. Final Drive. The system variables of the final drive are shown in Figure 3.

$$
\begin{aligned}
T_{w} & =T_{f} i_{f}+B_{f} \frac{\mathrm{d} \theta_{f}}{\mathrm{~d} t}+J_{f} \frac{\mathrm{d}^{2} \theta_{f}}{\mathrm{~d} t^{2}} \\
\theta_{f} i_{f} & =\theta_{g},
\end{aligned}
$$

where $J_{f}$ is the moment of inertia of the final drive, $\mathrm{kg} \cdot \mathrm{m}^{2} ; B_{f}$ is the damping coefficient of the final drive friction torque, $\mathrm{N} \cdot \mathrm{m} \cdot \mathrm{s} \cdot \mathrm{rad}^{-1} ; i_{f}$ is the final drive ratio; $T_{w}$ is the torque of wheels $\mathrm{N} \cdot \mathrm{m}$; and $\theta_{f}$ is the rotation angle of the final drive output shaft rad.

2.2.4. Wheels. The slip ratio of mobile dynamometer vehicle is ignored and the wheels are purely rolling. The transient dynamic analysis is performed on the entire system when the test tractor is loaded. Then, the following conclusions can be obtained:

$$
\begin{aligned}
T_{w} & +J_{w} \frac{\mathrm{d}^{2} \theta_{w}}{\mathrm{~d} t^{2}}+B_{w} \frac{\mathrm{d} \theta_{w}}{\mathrm{~d} t}+\delta_{t} M_{t} r_{t}^{2} \frac{\mathrm{d}^{2} \theta_{w}}{\mathrm{~d} t^{2}} \\
& =\left(F_{T}-F_{f t}\right) r_{t} \\
F_{t} & -F_{f b}-F_{T}=\delta_{b} M_{b} r_{t} \frac{\mathrm{d}^{2} \theta_{w}}{\mathrm{~d} t^{2}},
\end{aligned}
$$

where $J_{w}$ is the moment of inertia of the wheels, $\mathrm{kg} \cdot \mathrm{m}^{2}$; $B_{w}$ is the damping coefficient of the friction torque of the wheels, $\mathrm{N} \cdot \mathrm{m} \cdot \mathrm{s} \cdot \mathrm{rad}^{-1} ; F_{T}$ is the traction of the system, N; $F_{f t}$ is the rolling resistance of the mobile dynamometer, N; $r_{t}$ is the rolling radius of the driving wheels of the mobile dynamometer vehicle, $\mathrm{m} ; F_{t}$ is the driving force of the testing tractor, $\mathrm{N} ; F_{f b}$ is the rolling resistance of the tested tractor, $\mathrm{N}$; $\theta_{w}$ is the rotation angle of the driving wheels of the mobile dynamometer vehicle, $\mathrm{rad} ; M_{t}$ is the quality of the mobile dynamometer vehicle, $\mathrm{kg} ; M_{b}$ is the quality of the tested tractor, $\mathrm{kg} ; \delta_{b}$ is the conversion factor of tested tractor's revolving mass, $\delta_{b}>1$; and $\delta_{t}$ is the conversion factor of mobile dynamometer vehicle's revolving mass, $\delta_{t}>1$.

Based on the preceding summary, the following conclusions can be obtained:

$$
\begin{gathered}
J_{d} i_{g}^{2} i_{f}^{2} \frac{\mathrm{d}^{2} \theta_{w}}{\mathrm{~d} t^{2}}+T_{d} i_{g} i_{f}+J_{g} i_{f}^{2} \frac{\mathrm{d}^{2} \theta_{w}}{\mathrm{~d} t^{2}}+B_{g} i_{f}^{2} \frac{\mathrm{d} \theta_{w}}{\mathrm{~d} t} \\
+J_{f} \frac{\mathrm{d}^{2} \theta_{w}}{\mathrm{~d} t^{2}}+B_{f} \frac{\mathrm{d} \theta_{w}}{\mathrm{~d} t}+J_{w} \frac{\mathrm{d}^{2} \theta_{w}}{\mathrm{~d} t^{2}}+B_{w} \frac{\mathrm{d} \theta_{w}}{\mathrm{~d} t} \\
+\delta_{t} M_{t} r_{t}{ }^{2} \frac{\mathrm{d}^{2} \theta_{w}}{\mathrm{~d} t^{2}}=\left(F_{T}-F_{f t}\right) r_{t} .
\end{gathered}
$$

If we assume that $J_{\text {eq }}=J_{d} i_{g}^{2} i_{f}^{2}+J_{g} i_{f}^{2}+J_{f}+J_{w}, B_{\text {eq }}=B_{g} i_{f}^{2}+$ $B_{f}+B_{w}$, then

$$
\begin{aligned}
& J_{\text {eq }} \frac{\mathrm{d}^{2} \theta_{w}}{\mathrm{~d} t^{2}}+B_{\text {eq }} \frac{\mathrm{d} \theta_{w}}{\mathrm{~d} t}+T_{d} i_{g} i_{f}+\delta_{t} M_{t} r_{t}{ }^{2} \frac{\mathrm{d}^{2} \theta_{w}}{\mathrm{~d} t^{2}} \\
& =\left(F_{T}-F_{f t}\right) r_{t},
\end{aligned}
$$

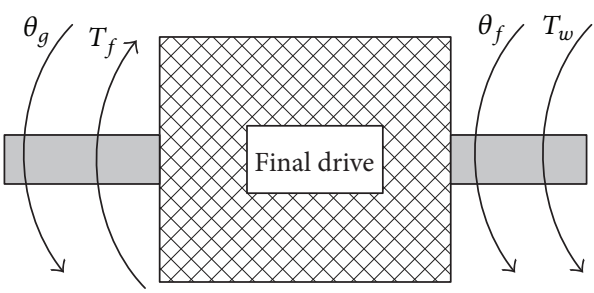

FIgURE 3: Variable symbols of the final drive.

where $J_{\text {eq }}$ is the equivalent moment of inertia, $\mathrm{kg} \cdot \mathrm{m}^{2}$, and $B_{\text {eq }}$ is the equivalent damping coefficient of friction torque, $\mathrm{N} \cdot \mathrm{m} \cdot \mathrm{s} \cdot \mathrm{rad}^{-1}$.

Assuming that the initial value of the system is zero, the rolling resistance is very small and can be ignored. Laplace transform is conducted for formulas (9) and (11), $\theta_{w}$ can be removed, and the result is as follows:

$$
\frac{F_{T}(s)}{T_{d}(s)}=\frac{i_{g} i_{f} \delta_{b} M_{b} r_{t} s}{\left[\left(\delta_{b} M_{b}+\delta_{t} M_{t}\right) r_{t}^{2}+J_{\mathrm{eq}}\right] s+B_{\mathrm{eq}}} .
$$

Based on the preceding summary, the transfer function of the entire system is shown as follows:

$$
\begin{aligned}
\frac{F_{T}(s)}{U(s)}= & \frac{2 k^{\prime} i_{g} i_{f} \delta_{b} M_{b} r_{t}}{\left[\left(\delta_{b} M_{b}+\delta_{t} M_{t}\right) r_{t}^{2}+J_{\mathrm{eq}}\right] s+B_{\mathrm{eq}}} \\
& \cdot \frac{1}{L s+R} e^{-\tau s} .
\end{aligned}
$$

\section{Design of the Neural Network PID Controller}

Frequently tuning the parameters is necessary if the nonlinearity, hysteresis, time-variation, and model uncertainty of the system are controlled by a traditional PID controller. The neural network control technology does not need the accurate mathematical model of the object and has fine selflearning and self-adaptation abilities. The parameters of the RBF-PID controller can be automatically corrected based on the changing conditions; therefore, control precision and response speed are improved $[15,16]$.

3.1. The RBF Neural Network Model. The RBF neural network function solves nonlinear problems, which change into linear ones, by mapping the low-dimension original space to the high-dimension feature space and approximating any continuous function with the weighted sum of multiple basis functions $[17,18]$. The RBF neural network structure is shown in Figure 4.

In the network structure, $X=\left[x_{1}, x_{2}, \ldots, x_{n}\right]^{\mathrm{T}}$, is the input, $H=\left[h_{1}, h_{2}, \ldots, h_{m}\right]^{\mathrm{T}}$ is the vector of radial basis, and $h_{j}$ is usually the Gauss function:

$$
h_{j}=\exp \left(-\frac{\left\|X-C_{j}\right\|^{2}}{2 b_{j}^{2}}\right) \quad(j=1,2, \ldots, m),
$$




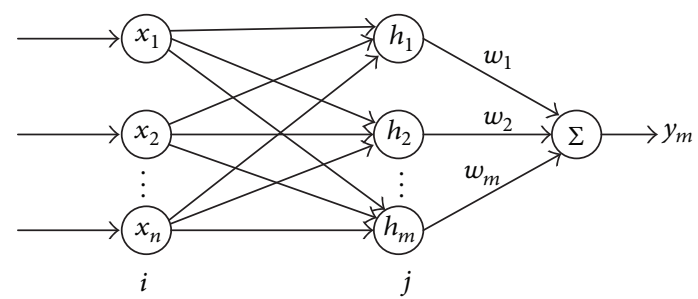

FIGURE 4: RBF neural network structure.

where $C_{j}=\left[c_{j 1}, c_{j 2}, \ldots, c_{j n}\right]^{\mathrm{T}}$ is the center vector of the $n$th node and $B=\left[b_{1}, b_{2}, \ldots, b_{m}\right]^{\mathrm{T}}$ is the width of the basis vector.

$W=\left[w_{1}, w_{2}, \ldots, w_{m}\right]^{\mathrm{T}}$ is the weight vector of the network, and the output of the network is shown as follows:

$$
y_{m}(k)=w_{1} h_{1}+w_{2} h_{2}+\cdots+w_{m} h_{m} .
$$

The optimization objective function of the identifier is shown as follows:

$$
J=\frac{1}{2}\left(y_{\text {out }}(k)-y_{m}(k)\right)^{2} .
$$

According to the gradient descent method, the iteration algorithms of the network parameters are as follows:

$$
\begin{aligned}
w_{j}(k)= & w_{j}(k-1)+\eta\left(y_{\text {out }}(k)-y_{m}(k)\right) h_{j} \\
& +\alpha\left(w_{j}(k-1)-w_{j}(k-2)\right) \\
\Delta b_{j}= & \left(y_{\text {out }}(k)-y_{m}(k)\right) w_{j} h_{j} \frac{\left\|X-C_{j}\right\|^{2}}{b_{j}^{3}} \\
b_{j}(k)= & b_{j}(k-1)+\eta \Delta b_{j}+\alpha\left(b_{j}(k-1)-b_{j}(k-2)\right) \\
\Delta c_{j i}= & \left(y_{\text {out }}(k)-y_{m}(k)\right) w_{j} \frac{x_{j}-c_{j i}}{b_{j}^{2}} \\
c_{j i}(k)= & c_{j i}(k-1)+\eta \Delta c_{j i} \\
& +\alpha\left(c_{j i}(k-1)-c_{j i}(k-2)\right),
\end{aligned}
$$

where $\eta$ is the learning rate and $\alpha$ is the momentum factor.

The Jacobin matrix indicates that, with regard to the sensitivity of the output to input changes, the algorithm is as follows:

$$
\frac{\partial y(k)}{\partial \Delta u(k)} \approx \frac{\partial y_{m}(k)}{\partial \Delta u(k)}=\sum_{j=1}^{m} w_{j} h_{j} \frac{c_{j i}-x_{1}}{b_{j}^{2}}
$$

where $x_{1}=\Delta u(k)$.

3.2. Control Principle of RBF-PID. The control principle of the loading system is shown in Figure 5. According to the experimental system proposed in this paper, the input is the desired traction; the output is the actual loading force, which is measured by drawing the force transducer; and the control object is the loading system. The RBF neural network realizes

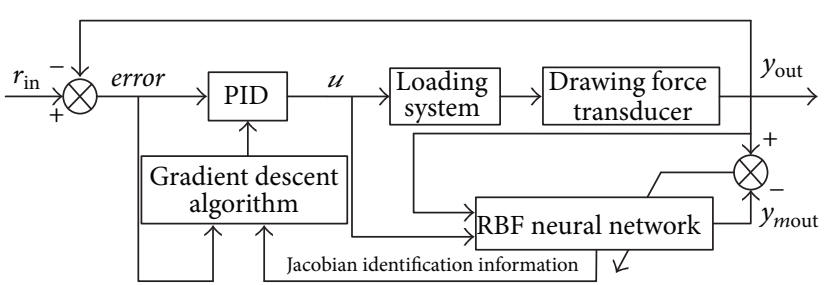

FIGURE 5: RBF-PID control principle.

online identification. The parameters of the PID controller are dynamically tuned in accordance with the identification information and optimization index.

The control algorithm uses the increasing type of PID. The error is shown as follows:

$$
\operatorname{error}(k)=r_{\text {in }}(k)-y_{\text {out }}(k)
$$

The algorithm is described as

$$
\begin{aligned}
& u(k)=u(k-1)+\Delta u(k) \\
& \Delta u(k) \\
& =k_{p}(\operatorname{error}(k)-\operatorname{error}(k-1))+k_{i} \operatorname{error}(k) \\
& \quad+k_{d}(\operatorname{error}(k)-2 \operatorname{error}(k-1)+\operatorname{error}(k-2)) .
\end{aligned}
$$

The optimization index of the neural network is

$$
E(k)=\frac{1}{2} \operatorname{error}(k)^{2} .
$$

$k_{p}, k_{i}$, and $k_{d}$ are tuned according to the gradient descent method.

$$
\begin{aligned}
& \Delta k_{p}=-\eta_{p} \frac{\partial E}{\partial k_{p}}=-\eta_{p} \frac{\partial E}{\partial y} \frac{\partial y}{\partial \Delta u} \frac{\partial \Delta u}{\partial k_{p}} \\
& =-\eta_{p} \operatorname{error}(k) \frac{\partial y}{\partial \Delta u}[\operatorname{error}(k)-\operatorname{error}(k-1)] \\
& \Delta k_{i}=-\eta_{i} \frac{\partial E}{\partial k_{i}}=-\eta_{i} \frac{\partial E}{\partial y} \frac{\partial y}{\partial \Delta u} \frac{\partial \Delta u}{\partial k_{i}}=-\eta_{i} \operatorname{error}(k) \frac{\partial y}{\partial \Delta u} \operatorname{error}(k) \\
& \Delta k_{d}=-\eta_{d} \frac{\partial E}{\partial k_{d}}=-\eta_{d} \frac{\partial E}{\partial y} \frac{\partial y}{\partial \Delta u} \frac{\partial \Delta u}{\partial k_{d}} \\
& =-\eta_{d} \operatorname{error}(k) \frac{\partial y}{\partial \Delta u}[\operatorname{error}(k)-2 \operatorname{error}(k-1)+\operatorname{error}(k-2)],
\end{aligned}
$$

where $\partial y / \partial \Delta u$ is the Jacobin information of the controlled object, which can be calculated by the neural network; $\eta_{p}$ is the learning rate of the proportional unit; $\eta_{i}$ is the learning rate of the integral unit; and $\eta_{d}$ is the learning rate of the differential unit.

\section{Simulation Analysis of Loading Control System}

The structure of the RBF neural network is 3-6-1, wherein $\Delta u(k), y_{\text {out }}(k)$, and $y_{\text {out }}(k-1)$ are inputs. After simulation and tests, the initialization parameters are determined as $\eta=0.25$, 
TABLE 1: Main parameters of the instruments.

\begin{tabular}{|c|c|c|}
\hline Name & $\begin{array}{c}\text { Type } \\
\text { specification }\end{array}$ & Main characteristics \\
\hline Wheel speed sensor & ZKE4006 & $\begin{array}{l}\text { Output waveform is square wave; the number of pulses is 1024; the maximum rotor } \\
\text { speed is } 6000 \mathrm{rpm} .\end{array}$ \\
\hline $\begin{array}{l}\text { Fuel consumption } \\
\text { meter }\end{array}$ & YH-DP2006 & $\begin{array}{l}\text { The measurement range is } 0.5-120 \mathrm{~L} / \mathrm{h} \text {; the maximum relative error is } 0.5 \% \text {; the } \\
\text { maximum pressure of output is } 800 \mathrm{kpa} \text {. }\end{array}$ \\
\hline $\begin{array}{l}\text { Engine revolution } \\
\text { speed sensor }\end{array}$ & $\mathrm{CZ} 400$ & $\begin{array}{l}\text { The measurement range is } 0-120000 \mathrm{rpm} \text {; the output signal is square wave; the } \\
\text { range of installation gap is } 0.5-3 \mathrm{~mm} \text {. }\end{array}$ \\
\hline $\begin{array}{l}\text { Drawing force } \\
\text { transducer }\end{array}$ & BLR-1/10000 & The measurement range is $0-10000 \mathrm{~kg}$; the allowable overload value is $20 \% \mathrm{RL}$. \\
\hline $\begin{array}{l}\text { Data collection } \\
\text { instrument }\end{array}$ & VDM-BS/TL & $\begin{array}{c}\text { The instrument is carried on a secondary development according to the } \\
\text { requirement. }\end{array}$ \\
\hline $\begin{array}{l}\text { GPS vehicle speed } \\
\text { sensor }\end{array}$ & DR-168SF & Tracking capability is $-159 \mathrm{dBm}$; the capture ability is $-148 \mathrm{dBm}$. \\
\hline $\begin{array}{l}\text { Wireless transmission } \\
\text { module }\end{array}$ & YL-500IW & $\begin{array}{l}\text { The communication speed is } 57600 \mathrm{bps} \text {; the transmission distance is longer than } \\
\qquad 3 \mathrm{~km} .\end{array}$ \\
\hline
\end{tabular}

$\alpha=0.04, k_{p}=15, k_{i}=0.1, k_{d}=0.1, \eta_{p}=0.68, \eta_{i}=0.68$, and $\eta_{d}=$ 0.35 . The initial value of the weight vector, the node center, and the width value of the basis function are shown as follows:

$$
\begin{aligned}
& W \\
& =[-0.5132,-0.9216,0.2853,0.6059,-0.2210,-0.3275]^{\mathrm{T}} ; \\
& C \\
& =\left[\begin{array}{c}
0.5862,0.6302,-0.8965,-2.0365,-2.1796,1.5864 \\
-0.9973,-0.3059,0.9928,0.5626,2.4058,0.5031 \\
-2.1451,-0.2095,1.6534,2.7786,1.0592,2.1782
\end{array}\right]^{\mathrm{T}} ; \\
& B=[1.5039,0.3736,2.6521,2.4361,02505,1.5362]^{\mathrm{T}} .
\end{aligned}
$$

A detailed simulation was conducted with MATLAB software. According to the characteristics of progressive loading, the traction is loaded from 0 to $10 \mathrm{kN}$. The response curves of two control strategies are shown in Figure 6. The RBF neural network PID, compared with traditional PID, effectively inhibits severe oscillation and realizes steady-state, error-free tracking.

\section{Verification of the Control Strategy by Vehicle Test}

All the selected instruments in the testing system are shown in Table 1.

The loading test of the YTO-MF554 tractor was conducted based on the designed testing system. The test picture is shown in Figure 7. The test pavement is concrete, the temperature is $20^{\circ} \mathrm{C}$, the pressure is $100.1 \mathrm{kPa}$, and the relative humidity is $65 \%$. The height of the traction point is $580 \mathrm{~mm}$ and the front and rear tire pressures are both $100 \mathrm{kPa}$.

The output traction data is acquired when the traction is loaded from 0 to $10 \mathrm{kN}$, drawing the target value and the actual output value curve shown in Figure 8. The traction error in the stability interval (1.5-10 s) is shown in Figure 9. As

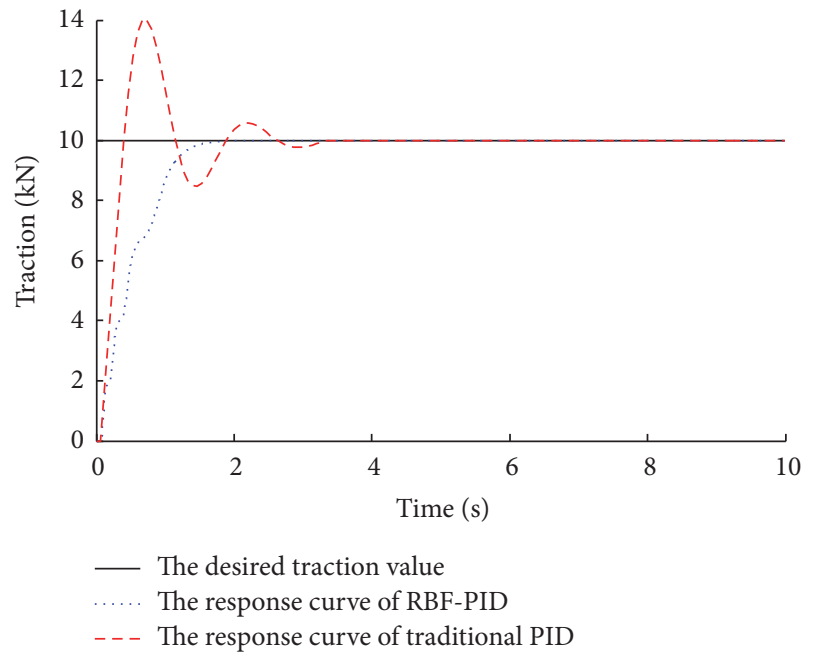

FIGURE 6: Comparison of response curves of two control strategies.

shown in Figures 8 and 9, the response time of the complete loading process is $1.5 \mathrm{~s}$, no obvious overshoot exists, the maximum traction error is $0.22 \mathrm{kN}$, and the traction mean value is $10.13 \mathrm{kN}$ in the stability interval. The parameters of the RBFPID controller are self-adjusted; therefore, the response speed is improved and the loading process is more stable. Moreover, the severe oscillation of the test system is avoided, which helps improve the test accuracy of each testing parameter.

\section{Conclusion}

(1) A RBF neural network for the PID control strategy of the mobile dynamometer vehicle loading system is designed. The structure and initial parameters of the RBF neural network are determined by a method that combined simulations and tests. RBF-PID can optimize PID parameters in real time. The simulation result shows that RBF-PID prevents the severe 


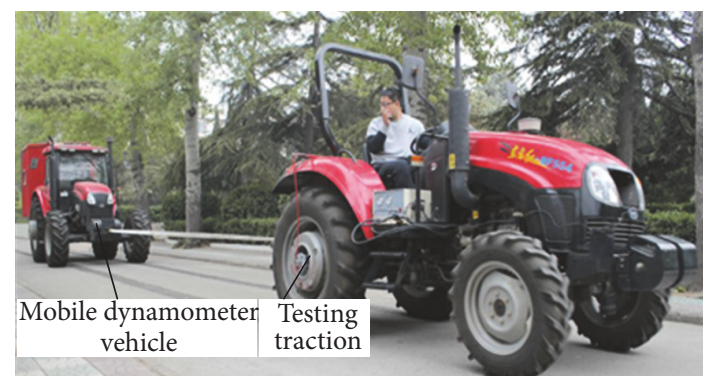

FIGURE 7: Traction test of YTO-MF554.

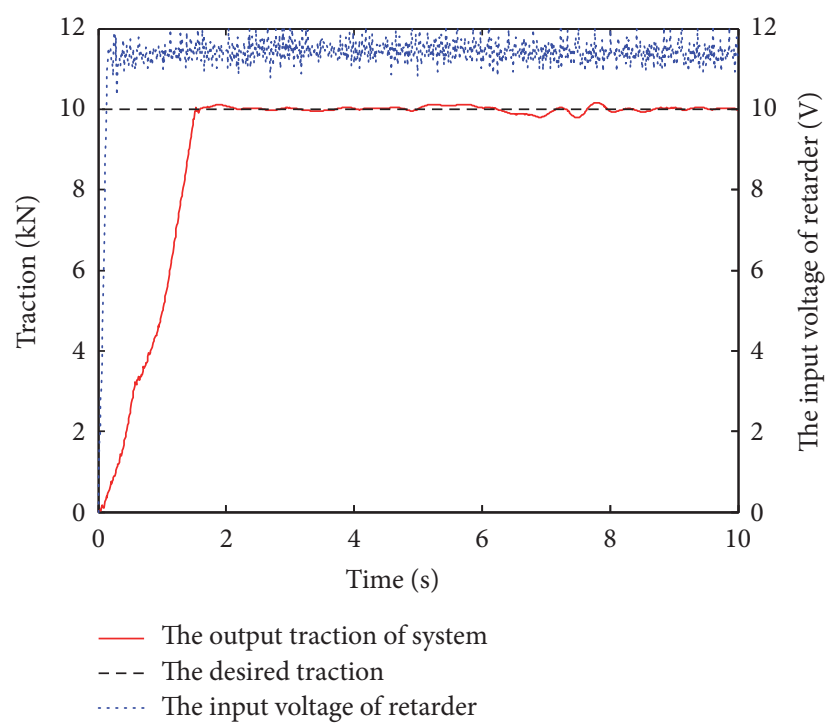

Figure 8: The change of system input, output, and retarder input voltage.

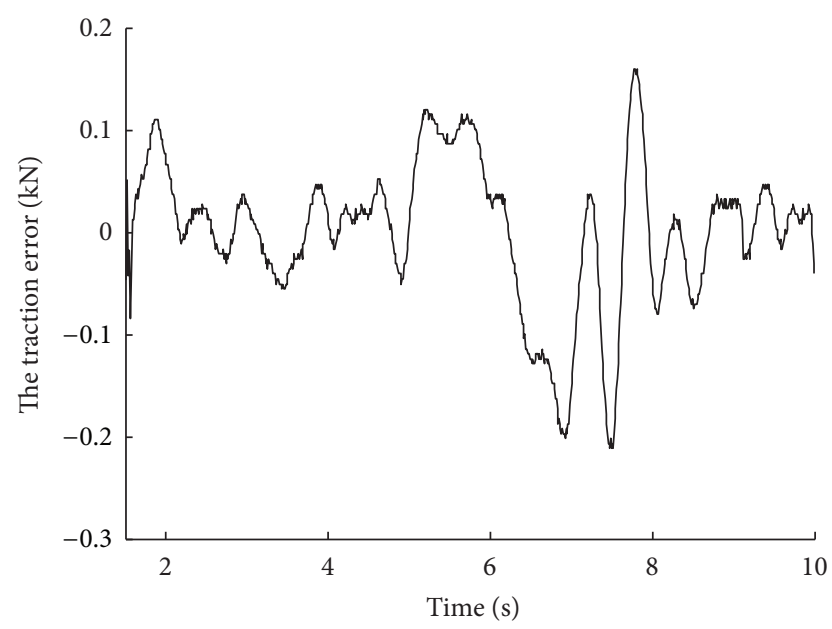

Figure 9: Traction error.

oscillation of the test system by improving the speed of dynamic response and steady-state precision of the system.

(2) Based on the RBF-PID controller design, the loading test of the YTO-MF554 tractor was conducted according to the regulations of the tractor traction performance test. In the test, the mobile dynamometer vehicle is loaded from
0 to $10 \mathrm{kN}$ and the loading time is $10 \mathrm{~s}$. The response time is $1.5 \mathrm{~s}$ and no obvious overshoot occurred during the loading process. The maximum traction error is $0.22 \mathrm{kN}$ and the mean traction value is $10.13 \mathrm{kN}$ in the stability interval. Test efficiency and precision are obviously improved. Frequently tuning the parameters of the controller is no longer necessary.

\section{Conflicts of Interest}

The authors declare that there are no conflicts of interest regarding the publication of this paper.

\section{Acknowledgments}

This research is supported by the 2016 National Key Research and Development Plan (no. 2016YFD0701002-2) and Key Technology Research Project of Henan Province (no. 102102210165).

\section{References}

[1] R. Hernández-Alvarado, L. G. García-Valdovinos, T. SalgadoJiménez et al., "Neural network-based self-tuning PID control for underwater vehicles," Sensors, vol. 16, no. 9, p. 1429, 2016.

[2] H. Rehman, "Detuning minimization of induction motor drive system for alternative energy vehicles," Energies, vol. 8, no. 9, pp. 9117-9136, 2015.

[3] D. C. Plaut and A. K. Vande Velde, "Statistical learning of parts and wholes: a neural network approach," Journal of Experimental Psychology: General, vol. 146, no. 3, pp. 318-336, 2017.

[4] L. Stefanazzi, F. Chierchie, E. E. Paolini, and A. R. Oliva, "Low distortion switching amplifier with discrete-time click modulation," IEEE Transactions on Industrial Electronics, vol. 61, no. 7, pp. 3511-3518, 2014.

[5] T. Y. Wang, C. L. Xiang, and M. X. Li, "Fuzzy auto tuning PID control strategy for the test system of the mobile dynamometer vehicle," Journal of Harbin Institute of Technology, vol. 6, pp. 997-1000, 2007.

[6] Y. Y. He, Q. F. Xu, and S. L. Yang, "A power load probability density forecasting method based on RBF neural network quantile regression," in Proceedings of the Canadian Society for Electrical Engineering (CSEE), vol. 1, pp. 93-98, 2003.

[7] C. L. Xia and M. C. Wang, "Single neuron PID control for switched reluctance motors based on RBF neural network," Proceedings of the CSEE, vol. 1, pp. 93-98, 2013.

[8] S. X. Wang, H. Yang, and X. X. Zhang, "A novel RBF-PID control strategy for fresh steam temperature based on chaotic and genetic algorithm," in Proceedings of the CSEE, vol. 23, pp. 87-92.

[9] S. Anwar, "A parametric model of an eddy current electric machine for automotive braking applications," IEEE Transactions on Control Systems Technology, vol. 12, no. 3, pp. 422-427, 2004.

[10] P. K. Dash, S. Mishra, and G. Panda, "A radial basis function neural network controller for UPFC", IEEE Transactions on Power Systems, vol. 15, no. 4, pp. 1293-1299, 2000.

[11] D. L. Yu and D. W. Yu, "Adaptive RBF model for model-based control," in Proceedings of the Congress on Intelligent Control and Automation, 82, 78 pages, Hangzhou:IEEE, 2004.

[12] W. M. Sun, Theoretical study on eddy current retarder [M.S. thesis], Beijing University of Technology, Beijing, China, 2005. 
[13] J. Y. Min, Research and Engineering Application of Test Technology for Exhaust Pollutants from Vehicles, Southeast University, 2006.

[14] S. Zeng, H. Hu, L. Xu, and G. Li, "Nonlinear adaptive PID control for greenhouse environment based on RBF network," Sensors (Switzerland), vol. 12, no. 5, pp. 5328-5348, 2012.

[15] W. Jia, D. Zhao, X. Liu, S. Tang, C. Ruan, and W. Ji, "Apple recognition based on $K$-means and GA-RBF-LMS neural network applicated in harvesting robot," Nongye Gongcheng Xuebao/Transactions of the Chinese Society of Agricultural Engineering, vol. 31, no. 18, pp. 175-183, 2015.

[16] G. S. Babu and S. Suresh, "Meta-cognitive RBF network and its projection based learning algorithm for classification problems," Applied Soft Computing Journal, vol. 13, no. 1, pp. 654666, 2013.

[17] H. Zhang and E. Sánchez-Sinencio, "Linearization techniques for CMOS low noise amplifiers: a tutorial," IEEE Transactions on Circuits and Systems. I. Regular Papers, vol. 58, no. 1, pp. 2236, 2011.

[18] M. Hayati, A. Lotfi, M. K. Kazimierczuk, and H. Sekiya, "Generalized design considerations and analysis of class-E amplifier for sinusoidal and square input voltage waveforms," IEEE Transactions on Industrial Electronics, vol. 62, no. 1, pp. 211-220, 2015. 


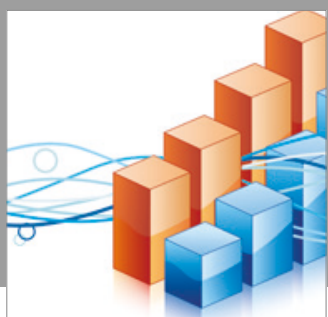

Advances in

Operations Research

vatersals

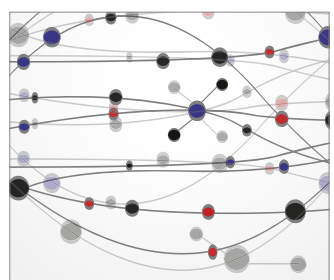

\section{The Scientific} World Journal
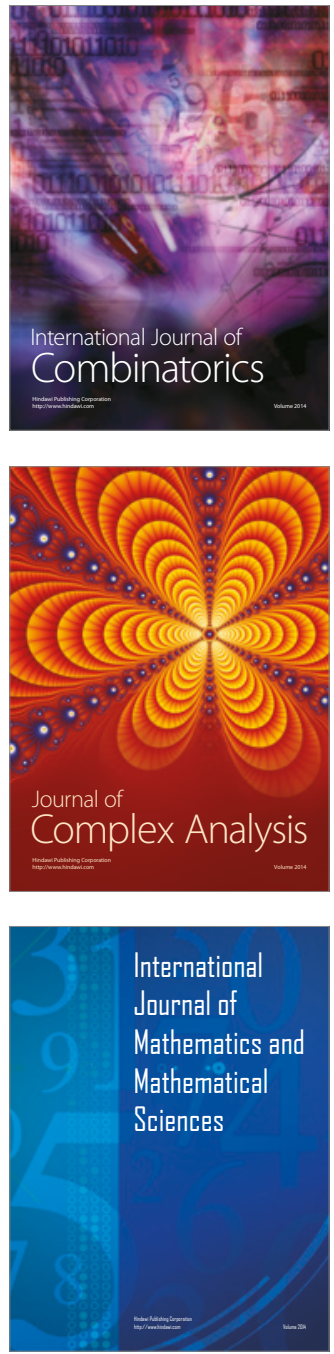
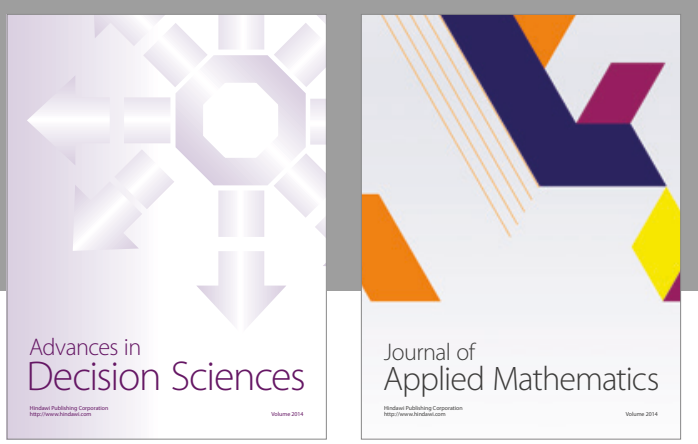

Algebra

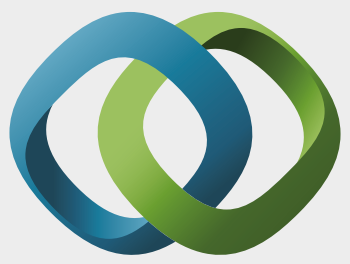

\section{Hindawi}

Submit your manuscripts at

https://www.hindawi.com
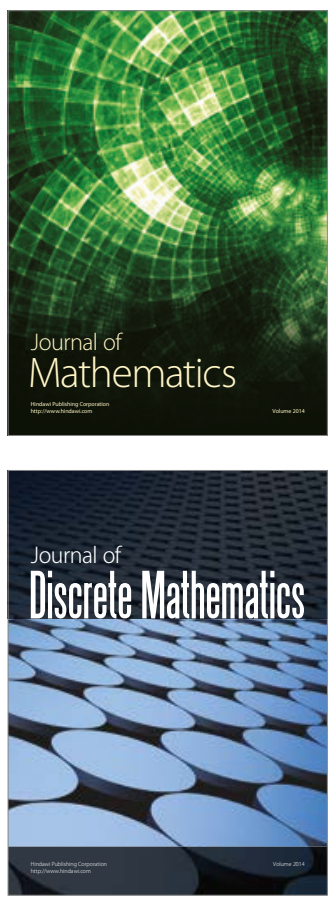

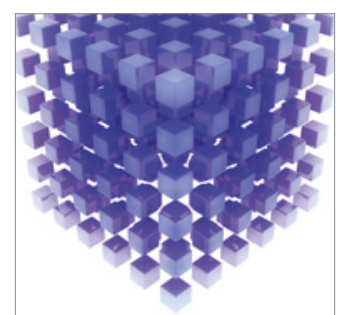

Mathematical Problems in Engineering
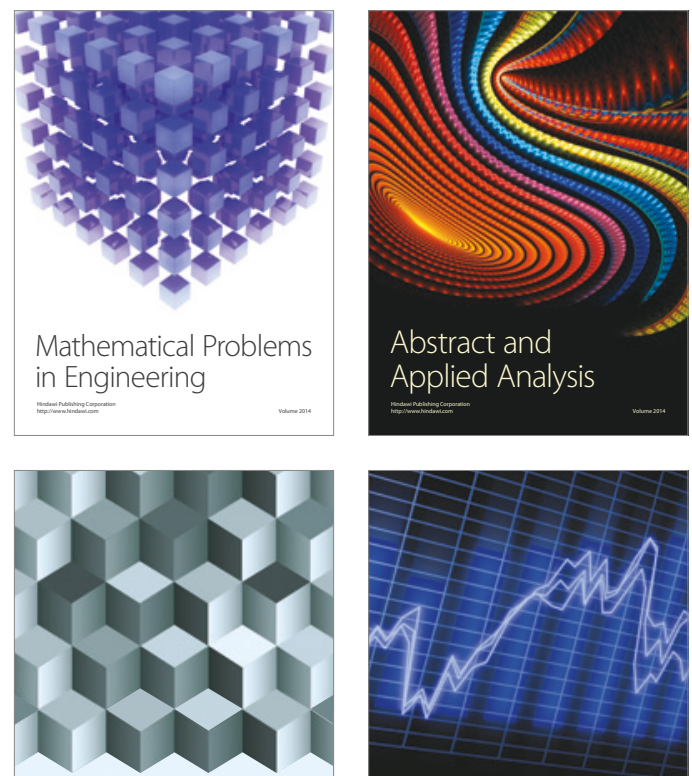

Journal of

Function Spaces

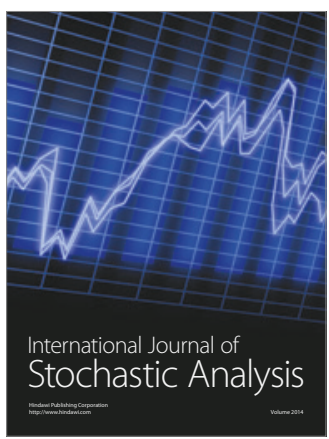

Probability and Statistics
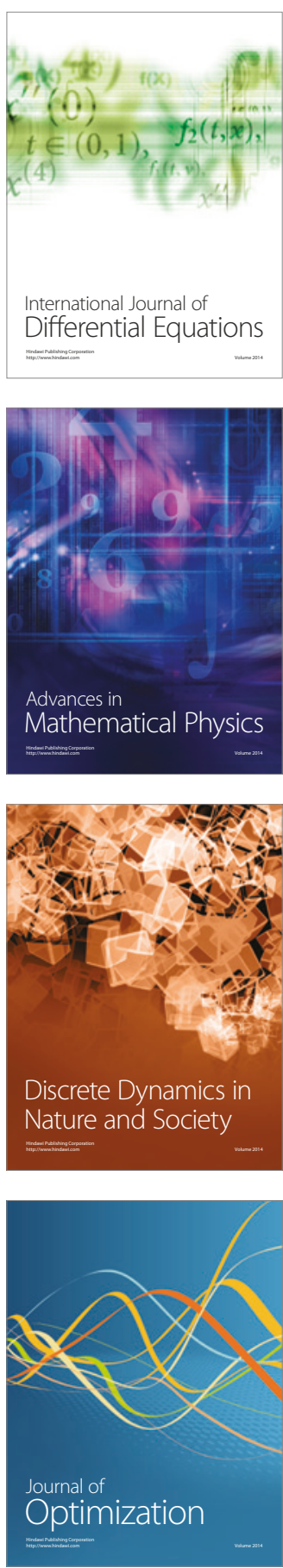